\title{
Enhancement of Cellulase
} Production in Trichoderma reesei via Disruption of Multiple Protease Genes Identified by Comparative Secretomics

\section{OPEN ACCESS}

Edited by:

Hui Wu,

East China University of Science and Technology, China

Reviewed by:

Xinqing Zhao,

Shanghai Jiao Tong University, China

Mukund Adsul,

DBT-IOC Centre for Advanced

Bio-Energy Research, India

Liya Liang,

University of Colorado Boulder,

United States

*Correspondence: Yaohua Zhong

zhongyaohua@sdu.edu.cn

Specialty section:

This article was submitted to Microbial Physiology and Metabolism,

a section of the journal

Frontiers in Microbiology

Received: 07 October 2019 Accepted: 15 November 2019 Published: 03 December 2019

Citation:

Qian Y, Zhong L, Sun Y, Sun N,

Zhang L, Liu W, Qu Y and Zhong Y (2019) Enhancement of Cellulase

Production in Trichoderma reesei via Disruption of Multiple Protease Genes Identified by Comparative Secretomics.

Front. Microbiol. 10:2784. doi: 10.3389/fmicb.2019.02784

\section{Yuanchao Qian', Lixia Zhong'2, Yu Sun', Ningning Sun', Lei Zhang ${ }^{3}$, Weifeng Liu', Yinbo $Q u^{1}$ and Yaohua Zhong ${ }^{1 *}$}

${ }^{1}$ State Key Laboratory of Microbial Technology, Institute of Microbial Technology, Shandong University, Qingdao, China, 2 Shandong Institute for Food and Drug Control, Jinan, China, ${ }^{3}$ Department of Immunology, School of Basic Medical Sciences, Shandong University, Jinan, China

The filamentous fungus Trichoderma reesei is one of the most studied cellulolytic organisms and the major producer of cellulases for industrial applications. However, undesired degradation of cellulases often happens in culture filtrates and commercial enzyme preparations. Even studies have been reported about describing proteolytic degradation of heterologous proteins in T. reesei, there are few systematic explorations concerning the extracellular proteases responsible for degradation of cellulases. In this study, the cellulase activity was observed to rapidly decrease at late cultivation stages using corn steep liquor (CSL) as the nitrogen source in T. reesei. It was discovered that this decrease may be caused by proteases. To identify the proteases, comparative secretomics was performed to analyze the concomitant proteases during the cellulase production. 12 candidate proteases from the secretome of $T$. reesei were identified and their encoding genes were individually deleted via homologous recombination. Furthermore, three target proteases (tre81070, tre120998, and tre123234) were simultaneously deleted by one-step genetic transformation. The triple deletion strain $\triangle$ P70 showed a $78 \%$ decrease in protease activity and a six-fold increase in cellulase activity at late fermentation stages. These results demonstrated the feasibility of improvement of cellulase production by genetically disrupting the potential protease genes to construct the $T$. reesei strains with low extracellular protease secretion. This dataset also provides an efficient approach for strain improvement by precise genetic engineering combined with "omics" strategy for high-production of industrial enzymes to reduce the cost of lignocellulose bioconversion.

Keywords: Trichoderma reesei, protease, cellulase, comparative secretomics, gene deletion

\section{INTRODUCTION}

The filamentous fungus Trichoderma reesei is one of the most investigated cellulolytic organisms for the robust capacity to produce the large amounts of lignocellulolytic enzymes (Cherry and Fidantsef, 2003). This complex enzyme system consists of cellulases, such as cellobiohydrolase $(\mathrm{CBH})$ and endo- $\beta$-1,4-glucanase (EG), and hemicellulases, such as xylanase (XYN), which 
cooperate to complete biomass hydrolysis (Singhania et al., 2013). In addition, the production of lignocellulolytic enzymes could achieve the level of $100 \mathrm{~g} / \mathrm{L}$ (Cherry and Fidantsef, 2003). So up to now, it is the dominant producer for production of the current commercial cellulase preparation (Singhania et al., 2013; Landowski et al., 2015). However, the truncated cellulases had been detected in the culture filtrates and the commercial enzyme preparations (Kubicek-Pranz et al., 1991; Collén et al., 2011). It was further demonstrated that the occurrence of truncated cellulases were probably due to their hydrolysis by proteases (Dienes et al., 2007). Therefore, the formation of extracellular proteases of T. reese $i$ is a limitation for the production of cellulase during the fermentation process. To overcome this problem, low-protease-level strains or protease-deficient strains should be developed or isolated to improve cellulase production.

Both random mutagenesis and genetic modification are the frequently used strategies for generating the fungal strains with increased or reduced levels of targeted products in filamentous fungi (Punt et al., 2008). Apparently, the random mutagenesis approach results in the potent production hosts, but the genetic bases of these mutants remain unknown and may have undesired effects on fungal fermentation performance, such as low growth rate (Peterson and Nevalainen, 2012). Compared with random mutagenesis, genetic modification provides a more rational approach to obtain the targeted strains. Actually, genetic modification has been applied to generate strains with reduced protease activity for increasing the protein production by Aspergillus sp. (Punt et al., 2008; Yoon et al., 2009; Sriranganadane et al., 2011). Recently, several studies with the genetic modification method have been carried out to generate the low-protease-level strains in $T$. reesei (Zhang et al., 2014; Landowski et al., 2016). The production of the heterologous alkaline EG was improved in the alkaline proteasedisrupted strain $T$. reesei $\Delta s p w 1$ (Zhang et al., 2014). Deletion of the subtilisin protease gene $s l p 7$ or the metalloprotease gene amp2 in $T$. reesei has enhanced the production level of heterologous IFN $\alpha-2 b$ (Landowski et al., 2016). Evidently, it is feasible to construct the protease deficient strains via the genetic manipulation for improving the production of extracellular protein in $T$. reesei. However, considering the heterologous proteins often subjected to degradation easier than homologous proteins (Zhang et al., 2014), these results may be not applied to the endogenous cellulase production in $T$. reesei. Indeed, two other acid proteases were identified to play a partial role in degradation of the homologous cellulase (Dienes et al., 2007). Therefore, more investigations are required to study the protease secretion profile during fermentation process for cellulase production in $T$. reesei. Such investigations are necessary to construct the protease-deficient strains for high-level production of cellulases.

Approximately, 200 genes involved in proteolytic degradation are present in the genome of $T$. reesei (Martinez et al., 2008). Considering the high number of putative proteases, it may be impractical to delete them all (Landowski et al., 2015). It is known that the fungal extracellular proteases could degrade protein into oligopeptides or free amino acids to provide the nitrogen source for fungal growth, particularly when nitrogen is limited. Thus, it seems unrealistic and inadvisable to construct the strains with no extracellular protease activities (Yoon et al., 2009). Therefore, identification of the specific proteases associated with cellulase degradation should be the prerequisite to construct the protease-deficient strains. Proteomics provides an excellent tool for discovering and identifying the secreted proteins under variable conditions (Adav et al., 2010, 2011). Particularly, the liquid chromatographytandem mass spectrometry (LC-MS/MS) has been shown to be one of the most efficient proteomics strategies for identification of thousands of proteins in a complex sample (Gong et al., 2015; Byrum et al., 2018). In this study, the LC-MS/MS method was employed to identify the extracellular proteases associated with cellulase degradation during fermentation process. The candidate protease genes were successively deleted and the low-protease-level $T$. reesei strain was finally constructed by knocking out the target protease genes with one-step genetic manipulation. This strain with the multiple protease deletions possessed the stable expression levels of endogenous cellulases and thus a more productive $T$. reesei strain suitable for cellulase production.

\section{MATERIALS AND METHODS}

\section{Strains and Culture Conditions}

Trichoderma reesei QM9414 $\Delta$ mus53, a hyper-cellulolytic strain with high-efficiency homologous recombination, was kindly provided by Häkkinen et al. (2014) and used as the host strain for gene deletion. All strains were cultured on potato dextrose agar (PDA) plates until generating spores. Equal concentrations of conidia $\left(10^{6}\right.$ spores per $\left.\mathrm{mL}\right)$ were inoculated into $50 \mathrm{~mL}$ of seed medium in $500 \mathrm{~mL}$ Erlenmeyer flasks and cultured at $200 \mathrm{rpm}$ and $30^{\circ} \mathrm{C}$ for $36 \mathrm{~h}$. Then the $10 \mathrm{~mL}$ of pre-cultures were transferred into $100 \mathrm{~mL}$ of the cellulase production medium $(\mathrm{CPM})$ in $500 \mathrm{~mL}$ Erlenmeyer flasks and were incubated at $200 \mathrm{rpm}$ and $30^{\circ} \mathrm{C}$. The fermentation supernatants were taken every $24 \mathrm{~h}$ for cellulase production assay. The composition of seed medium was as follows $(\mathrm{g} / \mathrm{L})$ : 10 glucose, $5\left(\mathrm{NH}_{4}\right)_{2} \mathrm{SO}_{4}, 15$ $\mathrm{KH}_{2} \mathrm{PO}_{4}, 0.6 \mathrm{CaCl}_{2} .2 \mathrm{H}_{2} \mathrm{O}, 0.5 \mathrm{MgSO}_{4} .7 \mathrm{H}_{2} \mathrm{O}$, and 2 peptone. The composition of CPM was as follows $(\mathrm{g} / \mathrm{L}): 20$ microcrystalline cellulose, $15 \mathrm{KH}_{2} \mathrm{PO}_{4}, 0.6 \mathrm{CaCl}_{2} .2 \mathrm{H}_{2} \mathrm{O}, 0.5 \mathrm{MgSO}_{4} .7 \mathrm{H}_{2} \mathrm{O}$, and $5\left(\mathrm{NH}_{4}\right)_{2} \mathrm{SO}_{4}$ or 20 corn steep liquor (CSL).

\section{Gelatin Zymography}

Gelatin zymography of protease activity was performed mainly by the previously described method with modification (Landowski et al., 2015). Briefly, crude enzymes were separated on $12 \%$ SDSPAGE with $0.1 \%$ gelatin (Dingguo Corp., Beijing, China). After running the gel, proteins in the gel were renatured two times for $30 \mathrm{~min}$ in $2.5 \%$ Triton X-100 and $50 \mathrm{mmol} / \mathrm{L}$ Tris-HCL and then washed by $50 \mathrm{mmol} / \mathrm{L}$ Tris-HCL to further remove the SDS. The zymogram gel was then allowed to incubate overnight in reaction buffer (50 mM sodium citrate, $\mathrm{pH}$ 5.5). Then, the gel was stained with Coomassie Blue (Thermo Scientific) and destined in 10\% acetic acid/ethanol. 


\section{Liquid Chromatography-Tandem Mass Spectrometry (LC-MS/MS)}

Liquid chromatography-tandem mass spectrometry was performed to identify the extracellular proteases according to the method previously described with some modifications (Song et al., 2016). The fermentation supernatants were centrifuged and then filtered through $0.22 \mu \mathrm{m}$ PES membrane (Millipore) to remove the mycelium. The proteins in the supernatant were precipitated by acetone and trichloroacetic acid. The resuspended precipitates were dissolved in ultrapure water. And then $100 \mu \mathrm{g}(>10 \mathrm{mg} / \mathrm{mL})$ of proteins were degenerated by $50 \mu \mathrm{L}$ of degeneration buffer $(0.5 \mathrm{M}$ Tris- $\mathrm{HCl}, 2.75 \mathrm{mM}$ ethylenediaminetetraacetic acid (EDTA), $6 \mathrm{M}$ guanidine- $\mathrm{HCl}$, $\mathrm{pH}$ 8.1) and reduced by $50 \mu \mathrm{L}$ of $1 \mathrm{M}$ dithiothreitol (DTT) at $37^{\circ} \mathrm{C}$ for $2 \mathrm{~h}$. Then, the proteins were alkylated by $50 \mu \mathrm{L}$ of $1 \mathrm{M}$ iodoacetamide for $1 \mathrm{~h}$ under the dark condition. The alkylated proteins were filtered and collected by the Microcon YM-10 centrifugal filter (Millipore Corporation, United States). After centrifugation, the proteins were digested by trypsin (Sigma, United States) at $37^{\circ} \mathrm{C}$ for overnight. The digested oligopeptides were desalted by the ZipTip C18 column (Millipore Corporation, United States) and were further dissolved in $10 \mu \mathrm{L}$ of elution buffer $[50 \%(\mathrm{v} / \mathrm{v})$ acetonitrile $(\mathrm{ACN})$ and $0.1 \%(\mathrm{v} / \mathrm{v})$ trifluoroacetic acid] and then were subjected to nanoelectrospray ionization, followed by tandem mass spectrometry (MS/MS) in an LTQ Orbitrap Velos Pro (Thermo Scientific ${ }^{\mathrm{TM}}$, United States) coupled inline to HPLC. The peptides were detected by the Orbitrap at a resolution of 60,000. Data resulting from LCMS/MS analysis of trypsin digested proteins were searched by proteome discovered software 1.4 (Thermo Fisher Scientific) with the SEQUEST using the T. reesei database ${ }^{1}$. Functional matching of identified proteins was conducted using SEQUEST. The MEROPS database was adopted for protease identification ${ }^{2}$.

\section{Gene Deletion}

To construct the protease gene-deletion strains, the gene knocked-out cassettes of 12 protease genes: tre22459, tre51365, tre77579, tre73897, tre77579, tre79809, tre81070, tre81517, tre103039, tre105808, tre120998, tre123234, and tre123244 were constructed using the double-joint PCR method as previously described (Yu et al., 2004). These cassettes containing the selectable marker $h p h$ flanked by the $5^{\prime}$ - and $3^{\prime}$-flanking regions of the corresponding protease genes (Supplementary Figure S3a) were transformed into the protoplasts of $T$. reesei with the PEG-mediated transformation method as described previously (Penttilä et al., 1987). For construction of the tripledeletion strain, three gene knocked-out cassettes for tre81070, tre120998, and tre123234 at the same molar concentration were simultaneously transformed into the protoplasts QM9414 $\Delta$ mus53. The transformants were directly screened on MM plates containing the $300 \mu \mathrm{g} / \mathrm{mL}$ hygromycin $\mathrm{B}$. The purified candidates were further performed though PCR or Southern blot analysis to verify if the corresponding protease genes locus were replaced by the knocked-out cassette. The primers used in

${ }^{1}$ http://genome.jgi-psf.org/Trire2

${ }^{2} \mathrm{https} / / /$ www.ebi.ac.uk/merops/ construction and verification of the corresponding gene deletions were listed in Supplementary Table S1.

\section{Southern Blot Analysis}

Transformants were subjected to Southern blot analysis to dissect the integration types of the gene knocked-out cassettes. The probes of the corresponding genes were amplified through PCR by using the probe primers (Supplementary Table S1). In detail, the primer pairs Probe-81070-F/Probe-81070-R, Probe-120998F/Probe-120998-R, and Probe-123234-F/Probe-123234-R were used to prepare for the probes of tre81070, tre120998, and tre 123234, respectively. The genomic DNA was digested by the restriction enzyme XhoI, separated on a $0.8 \%$ (wt/vol) agarose gel and then transferred to a nylon membrane (Hybond $\mathrm{N}+$, Amersham). Probe labeling, hybridization and detection were carried out according to the manufacturer's recommendations for the use of the DIG High Primer DNA Labeling and Detection Starter Kit I (Roche Applied Science, Mannheim, Germany).

\section{Fungal Growth}

To analyze the effect of different carbon sources or nitrogen sources on growth, equal concentrations of spores $\left(10^{6}\right.$ spores per $\mathrm{mL}$ ) were inoculated on the central of agar plates supplemented with $0.2 \%$ peptone used as nitrogen sources and $2.0 \%(\mathrm{w} / \mathrm{v})$ of the different carbon sources (glucose, lactose or glycerol) for 4 days at $30^{\circ} \mathrm{C}$. To evaluate the influence of the protease gene deletion on nitrogen utilization, equivalent amount of spores were inoculated on the central of agar plates that contained $2.0 \%$ glucose as carbon source and $2.0 \%(\mathrm{w} / \mathrm{v})$ of the casein, gelatin, milk or peptone the nitrogen sources at $30^{\circ} \mathrm{C}$ for 4 days. The colony diameters of the protease gene deletion strains and the parental strain QM9414 $\Delta$ mus53 were measured at 24, 44, 56, 68, and $76 \mathrm{~h}$ after incubation.

\section{Determination of Cellulase Activity, Protease Activity, and Protein Concentration}

The activities of Filter paper (total cellulase activity), EGs and xylanases were measured using Whatman No. 1 filter paper, $\mathrm{CMC}-\mathrm{Na}$ and xylan as substrates, respectively. Then reaction mixtures contained $50 \mathrm{mg}$ of filter paper, 1.0\% CMC-Na or 1.0\% xylan with $500 \mu \mathrm{L}$ of the suitably diluted enzyme fractions. These mixtures were then incubated at $50^{\circ} \mathrm{C}$ for $60 \mathrm{~min}$ (FPA) or $30 \mathrm{~min}$ (EGs and xylanases activities). The amount of reducing sugar released was determined using the DNS method (Ghose, 1987).

The activities of $\mathrm{CBHs}$ and $\beta$-glucosidase (BGL) were determined according to Ghose with modifications using p-nitrophenyl- $\beta$-D-cellobioside (pNPC) and p-nitrophenyl- $\beta$-Dglucopyranoside (pNPG) as substrates, respectively (Ghose, 1987). The diluted supernatants $(100 \mu \mathrm{L})$ were incubated with $50 \mu \mathrm{L}$ of $10 \mathrm{mM}$ pNPG or $10 \mathrm{mg} / \mathrm{mL}$ pNPG dissolved in $50 \mathrm{mM}$ acetate buffer $\left(\mathrm{pH} \mathrm{5.0)}\right.$ at $50^{\circ} \mathrm{C}$ for $30 \mathrm{~min}$. Then, $150 \mu \mathrm{L}$ of each sample was mixed with an equal volume of $10 \%$ sodium carbonate. The absorbance at $420 \mathrm{~nm}$ was measured. One unit of EGs or BGL activity was defined as the amount of enzyme releasing $1 \mu \mathrm{mol}$ of pNP per minute. 
Protease activity was measured as described previously with modifications (Lovrien et al., 1985). Briefly, the $100 \mu \mathrm{L}$ diluted supernatants were incubated with $400 \mu \mathrm{L}$ of $0.25 \%(\mathrm{w} / \mathrm{v})$ azocasein dissolved in $100 \mathrm{mM}$ phosphoric buffer $(\mathrm{pH} 7.2)$ at $37^{\circ} \mathrm{C}$ for $2 \mathrm{~h}$. Then, the reaction was terminated by the addition of $400 \mu \mathrm{L}$ of $10 \%$ trichloroacetic acid and then centrifuged at $10,000 \mathrm{rpm}$ for $10 \mathrm{~min}$. After centrifugation, $100 \mu \mathrm{L}$ of the supernatants were collected and mixed with $500 \mu \mathrm{L}$ of $10 \% \mathrm{Na}_{2} \mathrm{CO}_{3}$ to terminate the reactions and the absorbance was measured at $440 \mathrm{~nm}$. Control assay without enzyme was used as the blank. Total extracellular protein concentration was measured with the Bio-Rad Protein Assay Kit (Bio-Rad, United States) following the manufacturer's instructions.

\section{RESULTS AND DISCUSSION}

\section{Production of Extracellular Protein Decreased Significantly at Late Cultivation Stages in $T$. reesei}

The complex nitrogen sources, such as CSL and yeast extract, have been regarded as the popular organic nitrogen sources to improve the extracellular protein yields in filamentous fungi (Facciotti et al., 1991; Farid and El-Shahed, 1993; Pedersen and Nielsen, 2000). Especially, CSL is the preferred substrate for cellulase production due to its nutritional richness in organic nitrogen sources to promote fungal growth (Rana et al., 2014). To evaluate the effect of CSL on cellulase production, CSL was used as the nitrogen source to cultivate the hypercellulolytic strain QM9414 $\Delta$ mus53. As shown in Figure 1A, the concentration of extracellular protein reached $0.90 \mathrm{mg} / \mathrm{mL}$ with CSL as the nitrogen source, which was much higher than that with $\left(\mathrm{NH}_{4}\right)_{2} \mathrm{SO}_{4}(0.39 \mathrm{mg} / \mathrm{mL})$. Correspondingly, the highest cellulase activity $(1.70 \mathrm{IU} / \mathrm{mL})$ under CSL condition was obtained at $120 \mathrm{~h}$ of cultivation, which was also significantly higher than that in $\left(\mathrm{NH}_{4}\right)_{2} \mathrm{SO}_{4}(0.62 \mathrm{IU} / \mathrm{mL})$ (Figure 1B). However, the cellulase activity under CSL condition was rapidly decreased at late cultivation stages after $120 \mathrm{~h}$, where the cellulase production was reduced by $64 \%$ at $168 \mathrm{~h}$ in comparison to that at $120 \mathrm{~h}$ (Figure 1B).
Proteolytic degradation of cellulases and other extracellular proteins produced by $T$. reesei has been attributed to proteases (Eneyskaya et al., 1999). And a trypsin-like serine protease was identified as the major factor for Cel7B truncation in T. reesei (Dienes et al., 2007). Thus, the possible reason why a rapid decrease of cellulase activity occurred during the CSL cultivation in this study might be the extracellular proteases induced by CSL but not by $\left(\mathrm{NH}_{4}\right)_{2} \mathrm{SO}_{4}$. To test this hypothesis, the protease activities of the culture supernatants of $T$. reesei under conditions of CSL and $\left(\mathrm{NH}_{4}\right)_{2} \mathrm{SO}_{4}$ were measured. It was found that the protease activity increased significantly at $120 \mathrm{~h}$ in CSL while the protease activity was not changed in $\left(\mathrm{NH}_{4}\right)_{2} \mathrm{SO}_{4}$ (Figure 1C). Furthermore, the culture supernatants were assayed by SDS-PAGE and gelatin zymography. As shown in Figure 2A, the amount of protein significantly decreased after $120 \mathrm{~h}$ under CSL condition, while there was no decrease under $\left(\mathrm{NH}_{4}\right)_{2} \mathrm{SO}_{4}$ condition. As shown in Figure 2B, a small amount of proteases with relatively low molecular weight (30$50 \mathrm{kDa}$ ) were present before $120 \mathrm{~h}$ and much more proteases with relatively high molecular weight $(60-200 \mathrm{kDa})$ occurred after $120 \mathrm{~h}$ under CSL condition, while there was no band present under $\left(\mathrm{NH}_{4}\right)_{2} \mathrm{SO}_{4}$ condition. As for the reason for enhancement of protease activity, it was probably due to the lack of available preferred nitrogen sources in the media at the late cultivation stages and thus inducing the protease production. Taken together, the results suggested that there was a close correlation between the occurrence of extracellular proteases and the degradation of cellulases under CSL condition at late fermentation stages.

\section{Identification of the Proteases in the Secretome of $T$. reesei}

As mentioned above, there was a significant difference in the protease activities between $72 \mathrm{~h}$ (Q3) and $168 \mathrm{~h}$ (Q7). To determine the proteases in the Q3 and Q7 secretome, the total extracellular proteins from the culture supernatants were identified by LC-MS/MS. All proteins identified from Q3 and Q7 were listed in Supplementary Table S2 (Q3) and Supplementary Table S3 (Q7). The total number of extracellular proteins detected in Q3 and Q7 were 110 and 92, respectively. Among these proteins, 74 proteins were shared by Q3 and Q7, 36
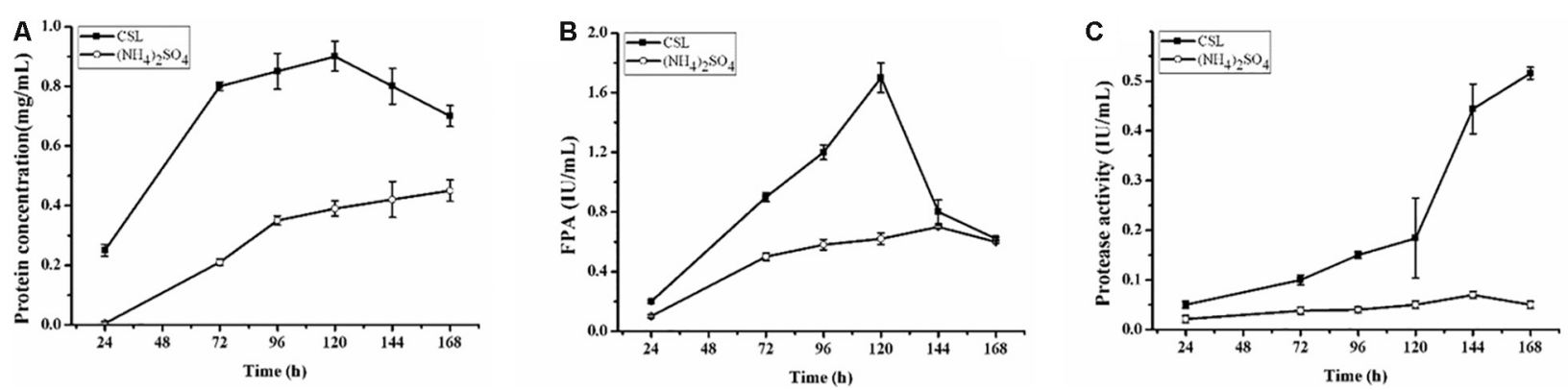

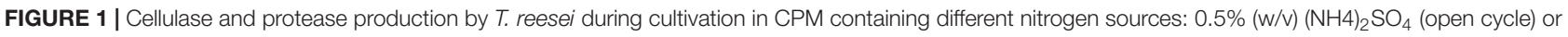
2.0\% corn steep liquor (CSL, filled square). (A) The extracellular protein produced by T. reesei was examined. (B) The total cellulase activities (FPA) were assayed.

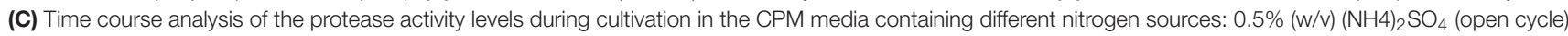
or $2.0 \%$ corn steep liquor (CSL, filled square). Data are the means of three independent experiments; error bars show standard deviations. 

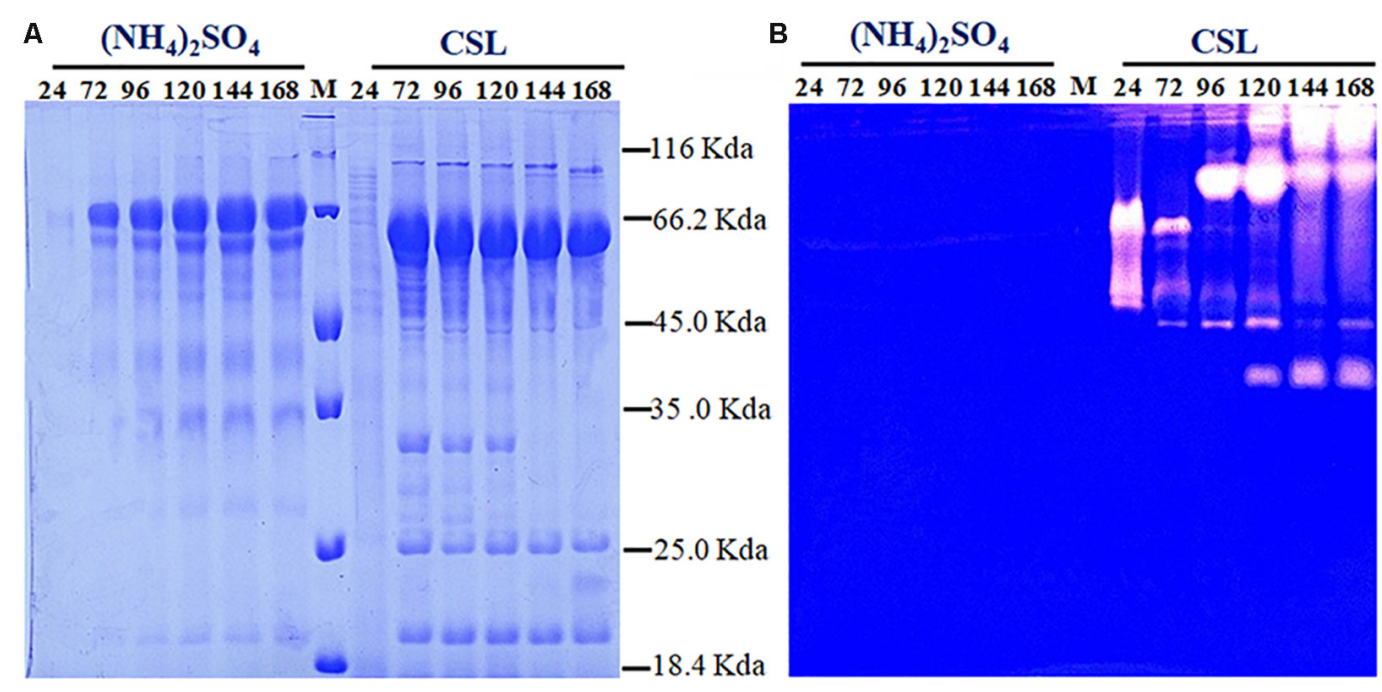

FIGURE 2 | Determination of the extracellular protein and protease activity of T. reesei. (A) SDS-PAGE analysis of the supernatants from T. reesei. (B) Gelatin zymography analysis of the proteases at different cultivation stages, including 24, 72, 96, 120, 144, and $168 \mathrm{~h}$, in the $\mathrm{CPM}$ media containing $\left(\mathrm{NH}_{4}\right)_{2} \mathrm{SO}_{4}$ or corn steep liquor (CSL). Data are the means of three independent experiments; error bars show standard deviations.

proteins were unique in Q3, and 18 proteins were specific for Q7 (Figure 3A). It was known that the peptide spectrum match (PSM) values were often used to represent the protein contents (Wang et al., 2017). According to the PSMs, the 10 proteins with the highest contents in Q3 and Q7 were selected and shown in Figures 3B,C, respectively. The majority of these proteins were related to degradation of lignocellulose, including $\mathrm{CBH} 1, \mathrm{CBH} 2$, $\mathrm{EG} 1$, and EG2. Especially, the ratio of $\mathrm{CBH} 1$ (PSM, 798) to $\mathrm{CBH} 2$ (PSM, 227) was 3.5 in Q3, whereas that is 2.26 in Q7. These results indicated that the cellulase components were changed at different cultivation stages.

Production of proteases could be not only influenced by the composition of medium, in particular the organic nitrogen, but also regulated by the $\mathrm{pH}$ of culture media (Haab et al., 1990; Delgado-Jarana et al., 2000). In T. reesei, an aspartic acid protease was identified to be correlated with cellulase degradation at $\mathrm{pH}$ below 5.0 (Haab et al., 1990). When the $\mathrm{pH}$ was controlled at 6.0, the trypsin-like alkaline serine protease Tvp1 was considered as the major factor in degrading CBH1 (Dienes et al., 2007). In the present study, the $\mathrm{pH}$ of the fermentation supernatant in CSL condition was 4.0 and 6.5 at the early (Q3) and late (Q7) cultivation stages, respectively. Correspondingly, 12 proteases belonging to different families were identified (Table 1). Among these proteases, four proteases including the trypsinlike serine protease (tre73897), the aspartic protease (tre79807), the aminopeptidase (tre81070), and the zinc metallopeptidase (tre105808) were unique in Q3, whereas two serine proteases including the subtilase like protease (tre51365) and subtilisinrelated protease (tre123234) were observed in Q7. In addition, six proteases (tre22459, tre77579, tre81517, tre103039, tre120998, and tre123244) belonging to aspartic protease, serine protease as well as carboxypeptidase were shared by Q3 and Q7. These results suggested that there was a significant difference in the protease components at different cultivation stages.
In the genome of T. reesei, approximately 200 genes involved in proteolytic degradation were annotated (Martinez et al., 2008). Furthermore, 39 proteases were found to be secreted and $\mathrm{pH}$ dependent, which were determined by proteomics (Adav et al., 2011). Landowski et al. (2015) systematically identified 13 major proteases that are responsible for degradation of therapeutic proteins. More recently, Daranagama et al. (2019) found that the expression of trichodermapepsin (TrAsP) encoding-gene trasp is more favorable in acidic conditions in a galactose medium. These studies in combination with the above results demonstrated that $T$. reesei possesses a complex proteolytic system displaying different types of proteases in different growth conditions.

\section{Analysis of Protease Activity in the Individual Protease Gene-Deletion Strains}

To determine which proteases were related to cellulase degradation, all the 12 protease-encoding genes identified by comparative secretomics were individually deleted in $T$. reesei QM9414 $\Delta$ mus53. PCR analysis revealed that each protease gene was indeed deleted without ectopic integration of the deletion cassette (data not shown). When these protease gene-deletion strains were grown using the different protein-including nitrogen sources, including peptone, milk, gelatin and casein, the growth rates of most of the protease gene-deletion strains were similar to that of the parental strain QM9414 $\Delta$ mus53 (Supplementary Figure S1), except that deletion of tre123244 resulted in poor growth and no sporulation (data not shown, and this strain was not investigated for further study). Similarly, these protease genedeletion strains also did not display significant difference in the growth rate from that of the parental strain on the tested carbon sources, including glucose, lactose, and glycerol (Supplementary Figure S2). The phenomenon that the protease-gene-deletion 


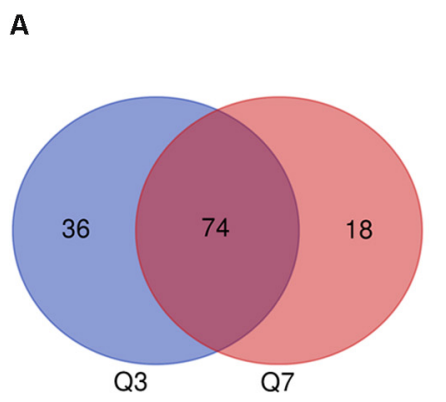

A

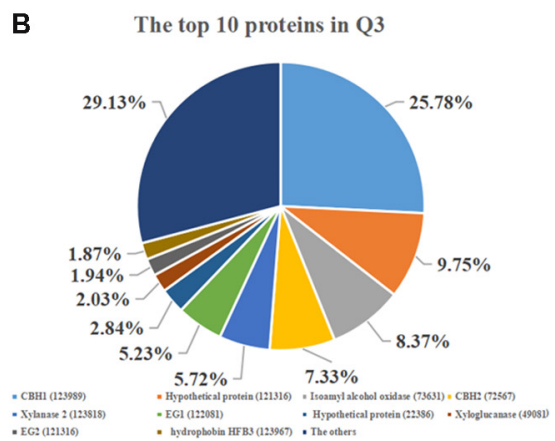

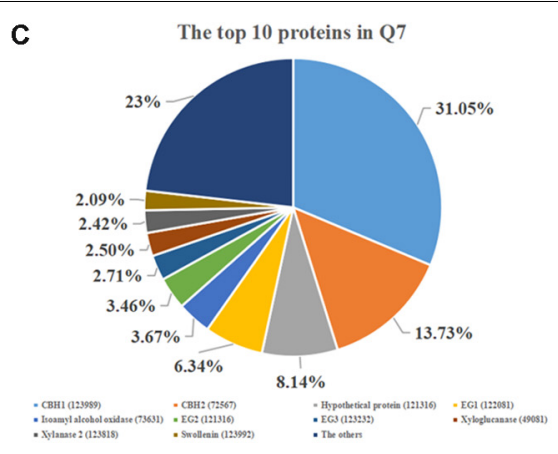

FIGURE 3 | The secreted proteins in the $72 \mathrm{~h}$ (Q3) and $168 \mathrm{~h}$ (Q7) fermentation supernatants of T. reesei identified by means of LC-MS/MS. (A) Venn diagram representing the number of secreted proteins by the T. reesei at $72 \mathrm{~h}$ (Q3) and $168 \mathrm{~h}$ (Q7) fermentation. (B) The main proteins secreted by T. reesei after $72 \mathrm{~h}$ of cultivation. (C) The main proteins secreted by T. reesei after $168 \mathrm{~h}$ of cultivation.

TABLE 1 | The proteases in the fermentation supernatants of T. reesei identified by means of LC-MS/MS.

\begin{tabular}{|c|c|c|c|c|c|c|}
\hline Protein ID & Description & AAs & MW (KDa) & Calc. pl & PSMs (Q3) & PSMs (Q7) \\
\hline tre73897 & Trypsin-like serine protease & 259 & 24.6 & 5.85 & 4 & \\
\hline tre79807 & Aspartyl protease & 516 & 52.1 & 4.80 & 2 & \\
\hline tre81070 & Aminopeptidase & 513 & 53.4 & 4.69 & 2 & \\
\hline tre105808 & Zinc metallopeptidases & 314 & 32.2 & 5.04 & 1 & \\
\hline tre22459 & Zinc carboxypeptidase & 442 & 45.6 & 6.42 & 1 & 2 \\
\hline tre77579 & Aspartyl protease & 395 & 42.4 & 4.74 & 5 & 7 \\
\hline tre81517 & Subtilisin & 1419 & 151.9 & 7.37 & 1 & 5 \\
\hline tre103039 & Serine-type peptidase & 268 & 28.7 & 4.75 & 2 & 3 \\
\hline tre120998 & Serine carboxypeptidase & 548 & 59.2 & 5.08 & 1 & 2 \\
\hline tre123244 & Serine protease-like protein & 541 & 56.5 & 5.49 & 7 & 12 \\
\hline tre51365 & Subtilase superfamily & 882 & 91.4 & 5.08 & & 1 \\
\hline tre123234 & Subtilisin-related protease & 391 & 38.9 & 5.83 & & 1 \\
\hline
\end{tabular}

PSM indicates the peptide spectrum match.

stains could grow normally or even faster on the complex media has also been observed previously (Landowski et al., 2015). The possible explanations for the normal or improved growth could be related to the enhanced stability of extracellular cellulases that can faster utilize sugars and thus facilitate the fungal growth (Landowski et al., 2015). Taken together, these results illustrated that most of the protease-gene deletions did not affect fungal growth on nitrogen sources or carbon sources in $T$. reesei.

To investigate the capacity to secrete proteases, these strains were cultured on the MM agar plates containing $1.0 \%$ skimmilk as the nitrogen substrate. It was found that these deletion strains exhibited the relatively smaller proteolytic halos around the colonies than that of the parental strain QM9414 4 mus53 (Figure 4A). Among these strains, $\Delta$ tre81070, $\Delta$ tre 120998 , and $\Delta$ tre 123234 exhibited the smallest halos. In accordance with this result, the ratios of proteolytic halo to colony diameter in the three strains were also the lowest ones (Figure 4B). These results clearly revealed that deletion of tre123234, tre120998 or tre 81070 significantly decreased the proteolytic capacities of T. reesei, demonstrating that tre81070, tre120998, and tre 123234 are probably the major extracellular proteases related to the decreased activity of cellulase in T. reesei.
To further investigate the protease activity of $\Delta$ tre81070, $\Delta$ tre 120998, and $\Delta$ tre123234 during the fermentation for cellulase production, the deletion strains were cultured in the $\mathrm{CPM}$ )at $30^{\circ} \mathrm{C}$ for 7 days. The culture supernatants were collected for the extracellular protease detection. As expected, $\Delta$ tre81070, $\Delta$ tre 120998 , and $\Delta$ tre123234 exhibited much lower protease activity than that of the parental strain QM9414Amus53 (Figure 4C). On the same time, the three mutants also produced relatively higher cellulase activities at late cultivation stages among the protease gene-deletion mutants (Figure 4D). Especially, the protease activity of $\Delta$ tre123234 showed a decrease of $55 \%$ in comparison with that of QM9414Amus53 using CSL as the nitrogen source at late fermentation stages. These results further suggested that the three extracellular proteases, tre81070, tre120998, and tre123234, contribute to the major protease activity in $T$. reesei during the fermentation in CPM medium containing CSL as the nitrogen source.

Serine proteases have been reported as the key factor for extracellular protein degradation in $T$. reesei (Landowski et al., 2015). Deletion of the serine protease gene spw1 (tre121495) resulted in a decrease on total extracellular protease activity (Zhang et al., 2014). Then the other two serine proteases SLP1 
A
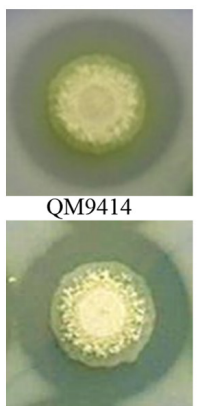

$\Delta 77579$

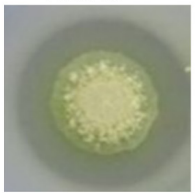

$\Delta 103039$

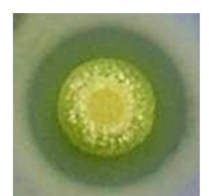

$\Delta 22459$

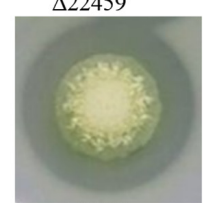

$\Delta 79807$

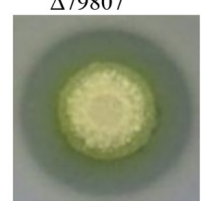

$\Delta 105808$

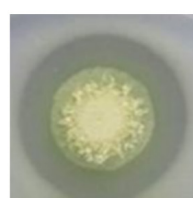

$\Delta 51365$
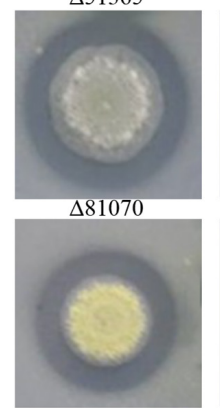

$\Delta 120998$

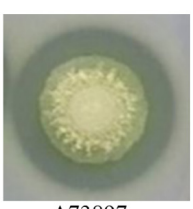

$\Delta 73897$

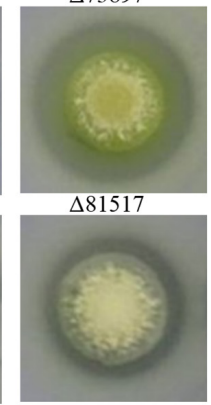

$\Delta 123234$

C

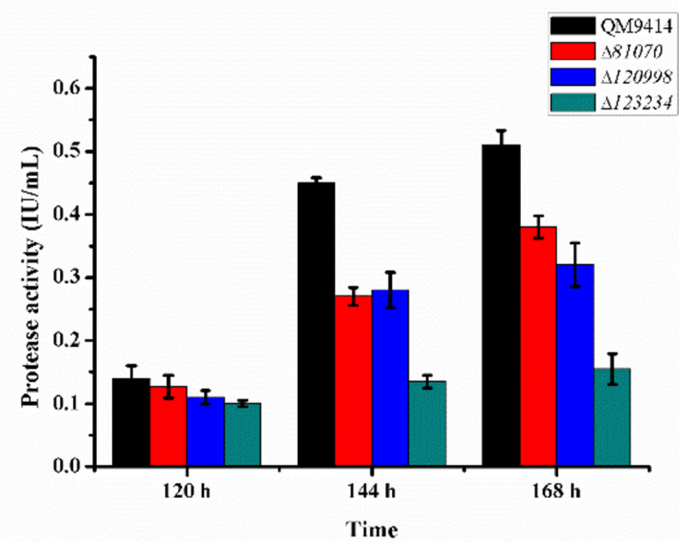

B

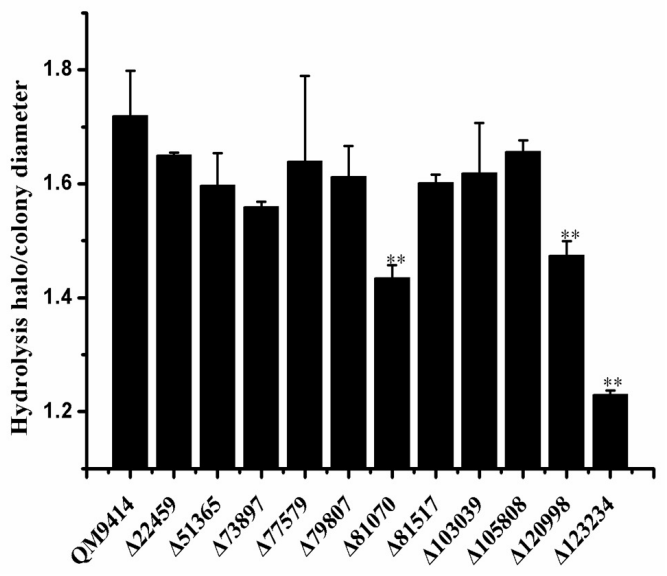

D

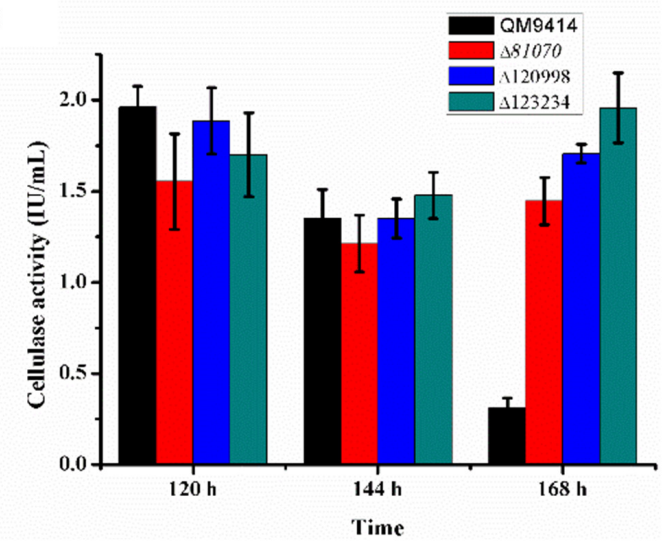

FIGURE 4 | Evaluation of the ability to produce proteases by the protease gene-deletion strains in T. reesei. (A) The 11 protease gene-deletion strains were grown on the media containing $1 \%$ skim milk. The halo size around the fungal colony reflected the extent of the milk hydrolysis due to the protease production. (B) The ratios of hydrolysis halo to colony diameter presented by panel (A). ${ }^{* *} P<0.01$. (C) Protease activities produced by the T. reesei protease gene-deletion strains $\Delta$ tre81070, $\Delta$ tre120998, $\Delta$ tre123234 and the parental strain QM9414 $\Delta$ mus53. (D) Protease activities produced by the T. reesei protease gene-deletion strains $\Delta$ tre81070, $\Delta$ tre120998, $\Delta$ tre123234 and the parental strain QM9414 $\Delta$ mus53.

(tre51365) and TSP1 (tre73897) were later identified to be most critical for degradation of antibody heavy chain (Landowski et al., 2015). However, Spw1 was not detected in this study while deletion of $\Delta$ tre51365 or $\Delta$ tre 73897 resulted in only a slight decrease in the protease activity, indicating the existence of additional serine proteases to support the extracellular protease activity. Here, tre123234 was found to be a serine protease at the late stage of fermentation and its gene deletion resulted in a 55\% decrease in protease activity, demonstrating that tre123234 is probably the major serine protease related to cellulase degradation in $T$. reesei. In our previous study, the GATA transcription factor Are1 was shown to play an important role in the regulation of proteases (Qian et al., 2019). Especially, the protease tre123244 was found to be the target protease that was regulated by Are1, and there were the conserved Are1binding sites in the promoter region of tre123244. Thus, it is speculated that tre123244 may be regulated by nitrogen sources. Furthermore, we inspected the yeast genome database with
TBLASTX by using the sequence of tre 123244 as the query. It was found that tre123244 has a high identity with the vacuole protease RB1 (NCBI YEL060C). PRB1 is shown to be involved in the proteolytic processing of the precursor proteins (Ogrydziak, 1993; Kerstens and Dijck, 2018). Therefore, it could be supposed that tre123244 is a vacuole protease and plays a key role in the basic cell metabolism.

\section{Simultaneous Disruption of the Triple Protease Genes in T. reesei}

Construction of industrially useful filamentous fungi require efficient genetic tools to perform time-saving sequential manipulations or multiplex manipulations. It was previously reported that the efficiency of homologous DNA integration in the $T$. reesei mus53 deletion strain was up to $100 \%$ in some cases (Steiger et al., 2011; Chum et al., 2017). This inspired us to suppose that homologous DNA integration into 
A

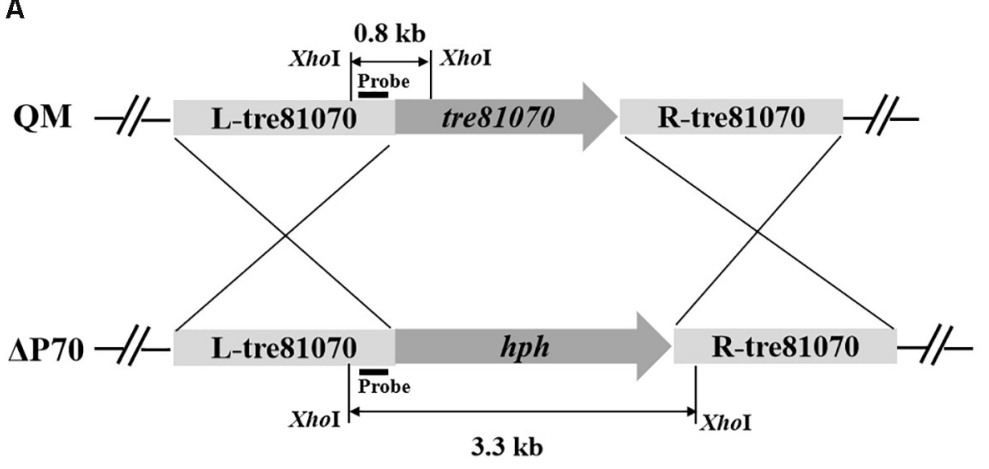

C

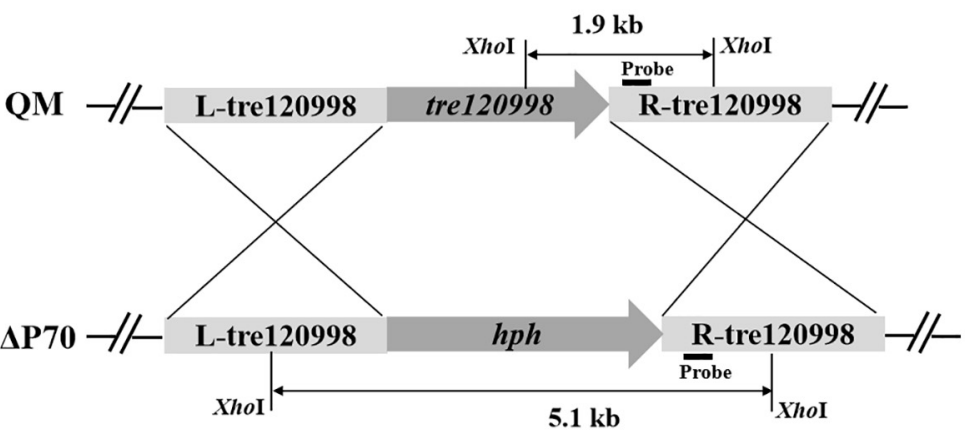

E

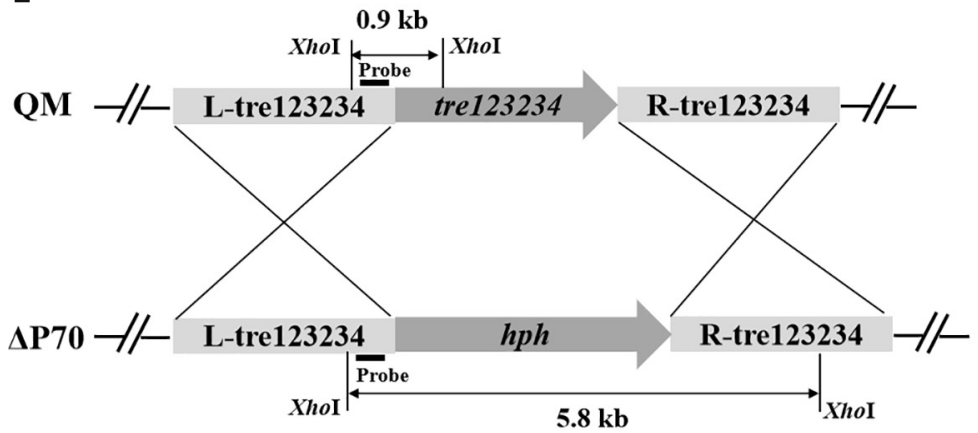

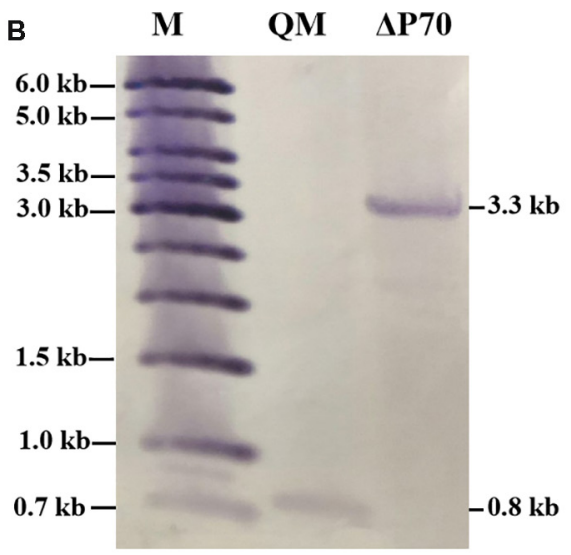

D $\quad M \quad Q M \quad \Delta P 70$

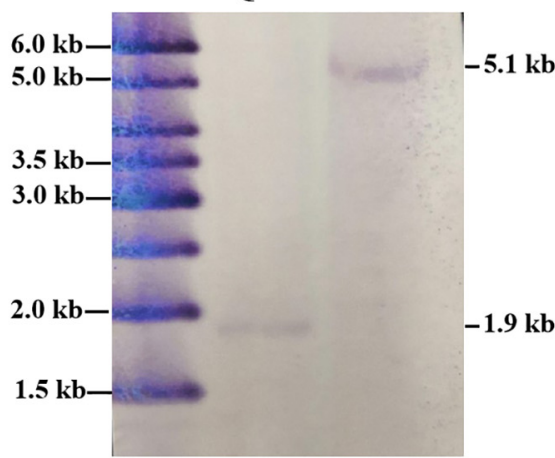

F $\quad$ M $\quad$ QM $\quad \Delta \mathbf{P 7 0}$

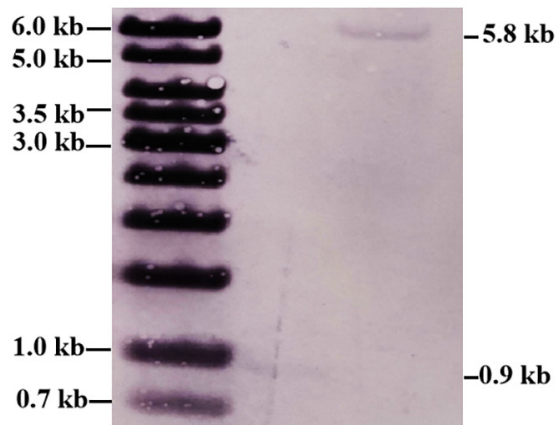

FIGURE 5 | Southern blot analysis of the triple protease-gene deletions in T. reesei $\triangle \mathrm{P} 70$. (A) Graphical representation of the genomic loci for the tre81070 deletion in T. reesei $\triangle \mathrm{P} 70$ and the parental strain QM9414 $\Delta$ mus53 (QM). (B) Southern blot of the Xhol-digested genomic DNA using a probe for detection of the tre81070 deletion event. A fragment of $0.8 \mathrm{~kb}$ is present in the parental strain while a $3.3 \mathrm{~kb}$ band is shown in $\Delta \mathrm{P} 70$. (C) Graphical representation of the genomic loci for the tre120998 deletion in T. reesei $\Delta$ P70 and QM9414 1 mus53 (QM). (D) Southern blot of the Xhol-digested genomic DNA using a probe for detection of the tre120998 deletion event. A fragment of $1.9 \mathrm{~kb}$ is present in the parental strain while a $5.1 \mathrm{~kb}$ band is shown in $\Delta \mathrm{P} 70$. (E) Graphical representation of the genomic loci for the tre123234 deletion in T. reesei $\Delta$ P70 and QM9414 $\Delta$ mus53 (QM). (F) Southern blot of the Xhol-digested genomic DNA using a probe for detection of the tre123234 deletion event. A fragment of $0.9 \mathrm{~kb}$ is present in the parental strain while a $5.8 \mathrm{~kb}$ band is shown in $\Delta \mathrm{P} 70$.

multiple genomic loci may occur in QM9414 $\Delta$ mus53. Thus, the selectable marker $h p h$ was used to simultaneously target three protease genes, tre81070, tre120998, and tre123234. After co-transformation of these three gene knock-out cassettes at the same molar concentration into the protoplasts of QM9414 $\Delta$ mus53, 80 transformants were selected from the MM plates containing $300 \mu \mathrm{g} / \mu \mathrm{L}$ hygromycin $\mathrm{B}$. Then these strains were verified through PCR analysis using the corresponding primer pairs (Supplementary Figures S3b-d). Among 80 hygromycin-resistant transformants, there were 32 single-genedeletion transformants, 20 double-gene-deletion transformants for $\Delta$ tre81070/ $\Delta$ tre120998, $10 \quad$ double-gene-deletion transformants for $\Delta$ tre81070/ $\Delta$ tre123234, 16 double-genedeletion transformants for $\Delta$ tre $120998 / \Delta$ tre 123234 , and two 

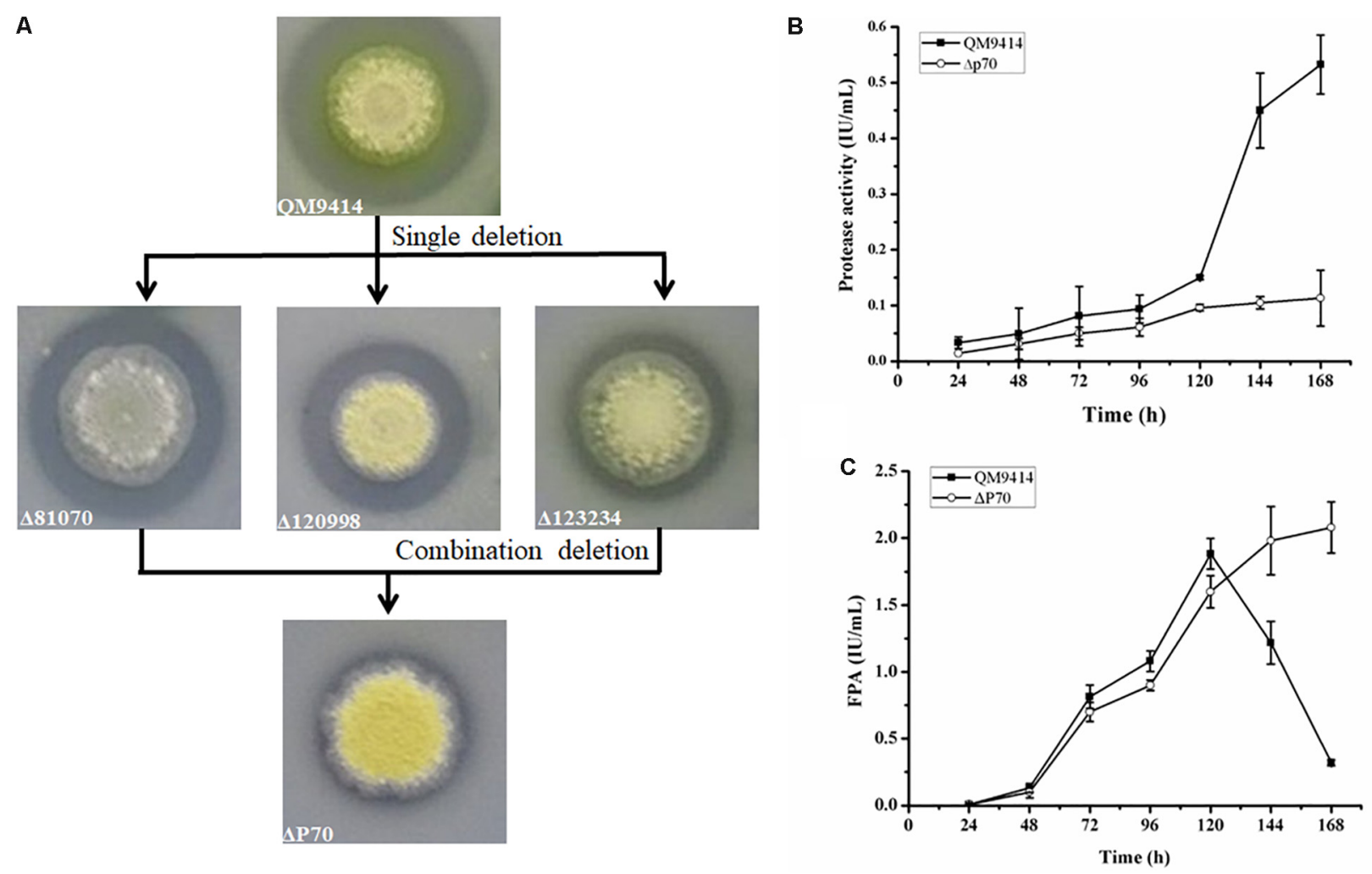

FIGURE 6 | Production of protease and cellulase by the triple protease gene-deletion strain $\Delta \mathrm{P} 70$. (A) The T. reesei protease gene-deletion strains were grown on the medium containing 1.0\% skim milk. (B) The protease activities produced by T. reesei $\Delta$ P70. (C) The total cellulase activity (FPA) produced by T. reesei $\Delta$ P70.

The values show the means of three biological replicates, and the error bars indicate the standard deviations.

transformants with triple gene deletions (namely, $\Delta \mathrm{P} 70$ and $\Delta$ P57). Although the frequency of triple deletions was quite low (2/80, i.e., 2.5\%), QM9414 $\Delta$ mus53 is a promising host to target multiple genes simultaneously at the genome. The triple gene-deletion strain $\Delta \mathrm{P} 70$ was further confirmed by Southern blot analysis. For the tre 81070 gene deletion, hybridization of XhoI-digested genomic DNA with the tre 81070 probe resulted in a $0.8 \mathrm{~kb}$ fragment in the parental strain QM9414 $\Delta$ mus53 while a $3.3 \mathrm{~kb}$ fragment in the $\Delta \mathrm{P} 70$ strain (Figures $\mathbf{5 A}, \mathbf{B}$ ). For the tre120998 gene deletion, hybridization with the tre120998

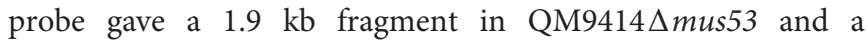
$5.1 \mathrm{~kb}$ fragment in $\Delta \mathrm{P} 70$ (Figures 5C,D). For the tre123234 gene deletion, Southern hybridization produced a $0.9 \mathrm{~kb}$ fragment for QM9414 $\Delta$ mus53 and a $5.8 \mathrm{~kb}$ fragment for $\triangle$ P70 (Figures 5E,F). These results demonstrated that the three protease genes, tre81070, tre120998, and tre123234, were successfully knocked out in the three-deletion strain $\triangle \mathrm{P} 70$. Subsequently, the $\Delta$ P70 strain was cultivated on the skim milk agar plate to test the ability to hydrolyze protein substrates (Figure 6A). The proteolytic halo around the colony of $\Delta \mathrm{P} 70$ was much smaller than those of $\Delta$ tre81070, $\Delta$ tre120998, $\Delta$ tre123234, and QM9414 $\Delta$ mus53. Furthermore, $\Delta$ P70 and the parental strain QM9414 $\Delta$ mus53 were fermented in CPM for 7 days, and the fermentation broths were used for enzyme activity assay. It was found that $\Delta \mathrm{P} 70$ exhibited a $78 \%$ decrease in the protease activity at late fermentation stages (168 h) (Figure 6B). These results illustrated that simultaneous disruption of the three protease genes, tre81070, tre120998, and tre123234, resulted in dramatic decrease of extracellular protease activity in $T$. reesei.

\section{Cellulase Production by the Triple-Protease Gene-Deletion Strain $\Delta$ P70}

Recently, Landowski et al. succeeded in decreasing the major extracellular proteases of $T$. reesei to make it as a more suitable system for therapeutic protein production (Landowski et al., 2015). However, after multiple protease deletions the total secreted protein was enhanced only around $22 \%$. This may suggest that there are more proteases in the culture supernatant that would need to be deleted to improve native cellulase production. Therefore, the cellulase production by the triple deletion strain $\triangle \mathrm{P} 70$ was performed in CPM for $168 \mathrm{~h}$, and the fermentation broths were used for cellulase activity assay. As shown in Figure 6C, the FPA of $\Delta$ P70 reached $2.08 \mathrm{IU} / \mathrm{mL}$, which was six-fold higher than that of QM9414 $\Delta$ mus53 $(0.32 \mathrm{IU} / \mathrm{mL})$, suggesting that degradation of cellulases was significantly alleviated at late fermentation stages in the triple-protease genedeletion strain $\triangle P 70$. The low-protease-level strains obtained recently by the genetic modification methods in $T$. reesei 

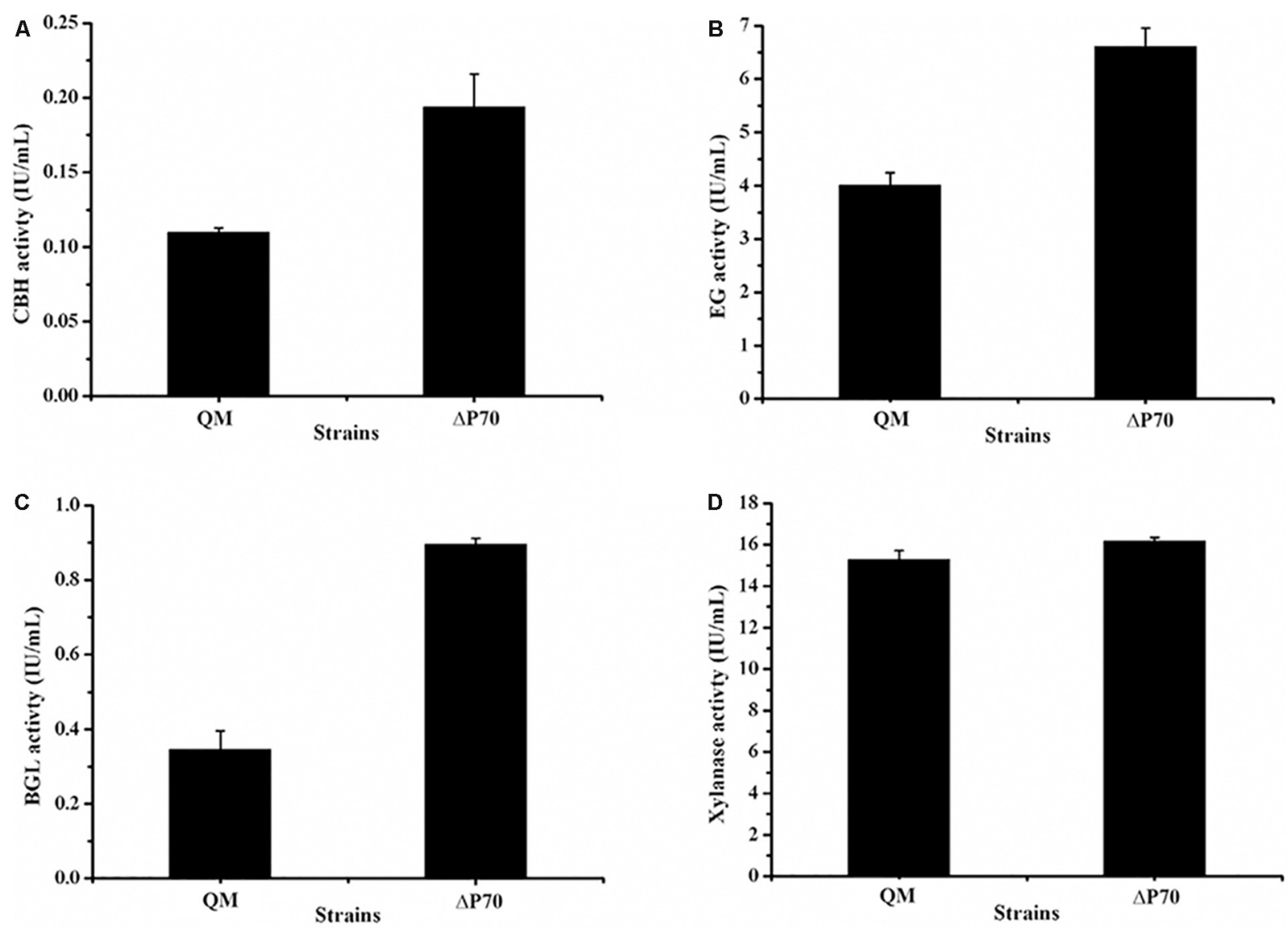

FIGURE 7 | The activities of lignocellulolytic component enzymes produced by the triple protease gene-deletion strain $\Delta$ P70. (A) The endo- $\beta$-1,4-glucanase (EG) activity. (B) The cellobiohydrolase $(\mathrm{CBH})$ activity. (C) The $\beta$-glucosidase (BGL) activity. (D) The xylanase activity. The values show the means of three biological replicates, and the error bars indicate the standard deviations.

were compared for the effect on cellulase/protein production (Supplementary Table S4). In addition, the $\beta$-glucosidase (BGL), $\mathrm{CBH}, \mathrm{EG}$, and xylanase activities in $\triangle \mathrm{P} 70$ exhibited $150 \%$, $75 \%, 65 \%$ and $6 \%$ higher than those of the parental strain QM9414 $\Delta$ mus53, respectively (Figure 7). Taken together, these results demonstrated that disruption of the major extracellular protease genes significantly increased cellulase production in $T$. reesei.

\section{CONCLUSION}

In this study, the cellulase activity produced by $T$. reesei was found to dramatically decreased at the late culture stages. Comparative secretomics strategy, combinated with multiplex gene manipulations, revealed the correlation between occurence of extracellular proteases and degradation of cellulases. The triple protease gene-deletion strain $\Delta \mathrm{P} 70$ is sufficient to support the high-level cellulase production. These results indicate that deletion of multiple protease genes is a feasible strategy for improvement of cellulase production to enhance bioconversion efficiency of lignocellulosic biomass.

\section{DATA AVAILABILITY STATEMENT}

All datasets generated for this study are included in the article/Supplementary Material.

\section{AUTHOR CONTRIBUTIONS}

YuQ and YZ conceived the work, drafted the manuscript, performed the experiments, and analyzed the data. LiZ, NS, and YS participated in the experiments and collected the data. LeZ, WL, YiQ, and YZ designed the work and revised the manuscript. All authors read and approved the final version of the manuscript.

\section{FUNDING}

This work was supported by the grants from the National Key R\&D Program of China (No. 2018YFA0900503), the National Natural Science Foundation of China (No. 31970070), the Fundamental Research Funds of Shandong University (No. 2018JC020), and the Postdoctoral Science Foundation of China (No. 2019M652372). 


\section{ACKNOWLEDGMENTS}

We thank Guodong Liu, Xuezhi Li, Zhonghai Li, Yuqi Qin, Xing Song, and Jian Zhao from Shandong University for helpful advice on this work.

\section{REFERENCES}

Adav, S. S., Li, A. A., Manavalan, A., Punt, P., and Sze, S. K. (2010). Quantitative iTRAQ secretome analysis of Aspergillus niger reveals novel hydrolytic enzymes. J. Proteome Res. 9, 3932-3940. doi: 10.1021/pr100148j

Adav, S. S., Ravindran, A., Chao, L. T., Tan, L., Singh, S., and Sze, S. K. (2011). Proteomic analysis of $\mathrm{pH}$ and strains dependent protein secretion of Trichoderma reesei. J. Proteome Res. 10, 4579-4596. doi: 10.1074/mcp.M111. 012419

Byrum, S. D., Loughran, A. J., Beenken, K. E., Orr, L. M., Storey, A. J., Mackintosh, S. G., et al. (2018). Label-free proteomic approach to characterize protease-dependent and -independent effects of sarA inactivation on the Staphylococcus aureus exoproteome. J. Proteome Res. 17, 3384-3395. doi: 10. 1021/acs.jproteome.8b00288

Cherry, J. R., and Fidantsef, A. L. (2003). Directed evolution of industrial enzymes: an update. Curr. Opin. Biotechnol. 14, 438-443. doi: 10.1016/s0958-1669(03) 00099-5

Chum, Y. P., Schmidt, G., Saloheimo, M., and Landowski, C. P. (2017). Transient silencing of DNA repair genes improves targeted gene integration in the filamentous fungus Trichoderma reesei. Appl. Environ. Microbiol. 83, 15-17. doi: 10.1128/AEM.00535-17

Collén, A., Ward, M., Tjerneld, F., and Stalbrand, H. (2011). Genetic engineering of the Trichoderma reesei endoglucanase I (Cel7B) for enhanced partitioning in aqueous two-phase systems containing thermoseparating ethylene oxidepropylene oxide copolymers. J. Biotechnol. 87, 179-191. doi: 10.1016/S01681656(01)00241-3

Daranagama, N. D., Shioya, K., Yuki, M., Sato, H., Ohtaki, Y., Suzuki, Y., et al. (2019). Proteolytic analysis of Trichoderma reesei in celluase-inducing condition reveals a role for trichodermapepsin (TrAsP) in cellulase production. J. Ind. Microbiol. Biotechnol. 46, 831-842. doi: 10.1007/s10295-019-02155-9

Delgado-Jarana, J., Pintor-Toro, J. A., and Benítez, T. (2000). Overproduction of $\beta$-1,6-glucanase in Trichoderma harzianum is controlled by extracellular acidic proteases and pH. Biochim. Biophys. Acta 1481, 289-296. doi: 10.1016/s01674838(00)00172-2

Dienes, D., Borjesson, J., Hagglund, P., Tjerneld, F., Liden, G., Reczey, K., et al. (2007). Identification of a trypsin-like serine protease from Trichoderma reesei QM9414. Enzyme Microb. Technol. 40, 1087-1094. doi: 10.1016/j.enzmictec. 2006.08.013

Eneyskaya, E. V., Kulminskaya, A. A., Savel'ev, A. N., Savel'eva, N. V., Shabalin, K. A., and Neustroev, K. N. (1999). Acid protease from Trichoderma reesei: limited proteolysis of fungal carbohydrases. Appl. Microbiol. Biotechnol. 52, 226-231.

Facciotti, M., Wuhstrack, G. H., Tonso, A., Chiquetto, M. L., and Schmidell, W. (1991). Effect of yeast extract on glucoamylase synthesis by Aspergillus awamori NRRL 3112. Biotechnol. Lett. 13, 547-552. doi: 10.1007/BF01033407

Farid, M. A., and El-Shahed, K. Y. (1993). Cellulase production on high levels of cellulose and corn steep liquor. Zentralbl. Mikrobiol. 148, 277-283. doi: 10.1016/s0232-4393(11)80104-6

Ghose, T. K. (1987). Measurement of cellulase activities. Pure Appl. Chem. 59, 257-268. doi: 10.1351/pac198759020257

Gong, W., Zhang, H., Liu, S., Zhang, L., Gao, P., Chen, G., et al. (2015). Comparative secretome analysis of Aspergillus niger, Trichoderma reesei, and Penicillium oxalicum during solidstate fermentation. Appl. Biochem. Biotechnol. 177, 1252-1271. doi: 10.1007/s12010-015-1811-z

Haab, D., Hagspiel, K., Szakmary, K., and Kubicek, C. P. (1990). Formation of the extracellular proteases from Trichoderma reesei QM9414 involved in cellulase degradation. J. Biotechnol. 16, 187-198. doi: 10.1016/0168-1656(90)90035-A

Häkkinen, M., Valkonen, M. J., Westerholm-Parvinen, A., Aro, N., Arvas, M., Vitikainen, M., et al. (2014). Screening of candidate regulators for cellulase and hemicellulase production in Trichoderma reesei and identification of a factor

\section{SUPPLEMENTARY MATERIAL}

The Supplementary Material for this article can be found online at: https://www.frontiersin.org/articles/10.3389/fmicb. 2019.02784/full\#supplementary-material

essential for cellulase production. Biotechnol. Biofuels. 7:14. doi: 10.1186/17546834-7-14

Kerstens, W., and Dijck, P. V. (2018). A cinderella story: how the vacuolar proteases Pep4 and Prb1 do more than cleaning up the cell's mass degradation processes. Microb. Cell 5, 438-443. doi: 10.15698/mic2018.10.650

Kubicek-Pranz, E., Gsur, A., Hayn, M., and Kubicek, C. (1991). Characterization of commercial Trichoderma reesei cellulase preparations by denaturing electrophoresis (SDS-PAGE) and immunostaining using monoclonal antibodies. Biotechnol. Appl. Biochem. 14, 317-323. doi: 10.1111/j.14708744.1991.tb00184.x

Landowski, C. P., Huuskonen, A., Wahl, R., Westerholm-Parvinen, A., Kanerva, A., Hanninen, A. L., et al. (2015). Enabling low cost biopharmaceuticals: a systematic approach to delete proteases from a well-known protein production host Trichoderma reesei. PLoS One 10:e0134723. doi: 10.1371/journal.pone. 0134723

Landowski, C. P., Mustalahti, E., Wahl, R., Croute, L., Sivasiddarthan, D., Westerholm-Parvinen, A., et al. (2016). Enabling low cost biopharmaceuticals: high level interferon alpha-2b production in Trichoderma reesei. Microb. Cell Fact. 15:104. doi: 10.1186/s12934-016-0508-5

Lovrien, R. E., Gusek, T., and Hart, B. (1985). Cellulase and protease specific activities of commercially available cellulase preparations. J. Appl. Biochem. 7, 258-272. doi: 10.1104/pp.89.1.138

Martinez, D., Berka, R. M., Henrissat, B., Saloheimo, M., Arvas, M., Baker, S. E. et al. (2008). Genome sequencing and analysis of the biomass-degrading fungus Trichoderma reesei (syn. Hypocrea jecorina). Nat. Biotechnol. 26, 553-560. doi: $10.1038 /$ nbt1403

Ogrydziak, D. M. (1993). Yeast extracellular proteases. Crit. Rev. Biotechnol. 13, 1-55. doi: 10.3109/07388559309069197

Pedersen, F., and Nielsen, ÁJ. (2000). The influence of nitrogen sources on the a-amylase productivity of Aspergillus oryzaein continuous cultures. Appl. Microbiol. Biotechnol. 53, 278-281. doi: 10.1007/s002530050021

Penttilä, M., Nevalainen, H., Rättö, M., Salminen, E., and Knowles, J. (1987). A versatile transformation system for the cellulolytic filamentous fungus Trichoderma reesei. Gene 61, 155-164. doi: 10.1016/0378-1119(87)90110-7

Peterson, R., and Nevalainen, H. (2012). Trichoderma reesei RUT-C30-thirty years of strain improvement. Microbiology 158, 58-68. doi: 10.1099/mic.0.054031-0

Punt, P. J., Schuren, F. H., Lehmbeck, J., Christensen, T., Hjort, C., and van den Hondel, C. A. (2008). Characterization of the Aspergillus niger prtT, a unique regulator of extracellular protease encoding genes. Fungal Genet. Biol. 45, 1591-1599. doi: 10.1016/j.fgb.2008.09.007

Qian, Y., Sun, Y., Zhong, L., Sun, N., Sheng, Y., Qu, Y., et al. (2019). The GATA-type transcriptional factor Are1 modulates the expression of extracellular proteases and cellulases in Trichoderma reesei. Int. J. Mol. Sci. 20:4100. doi: 10.3390/ ijms 20174100

Rana, V., Eckard, A. D., Teller, P., and Ahring, B. K. (2014). On-site enzymes produced from Trichoderma reesei RUT-C30 and Aspergillus saccharolyticus for hydrolysis of wet exploded corn stover and loblolly pine. Bioresour. Technol. 154, 282-289. doi: 10.1016/j.biortech.2013.12.059

Singhania, R. R., Patel, A. K., Sukumaran, R. K., Larroche, C., and Pandey, A. (2013). Role and significance of beta-glucosidases in the hydrolysis of cellulose for bioethanol production. Bioresour. Technol. 127, 500-507. doi: 10.1016/j. biortech.2012.09.012

Song, W. X., Han, X. L., Qian, Y. C., Liu, G. D., Yao, G. S., Zhong, Y. H., et al. (2016). Proteomic analysis of the biomass hydrolytic potentials of Penicillium oxalicum lignocellulolytic enzyme system. Biotechnol. Biofuels 9:68. doi: 10.1186/s13068016-0477-2

Sriranganadane, D., Reichard, U., Salamin, K., Fratti, M., Jousson, O., Waridel, P., et al. (2011). Microbiology-secreted glutamic protease rescues aspartic protease Pep deficiency in Aspergillus fumigatus during growth in acidic protein medium. Microbiology 157, 1541-1550. doi: 10.1099/mic.0.048603-0 
Steiger, M. G., Vitikainen, M., Uskonen, P., Brunner, K., Adam, G., Pakula, T., et al. (2011). Transformation system for Hypocrea jecorina (Trichoderma reesei) that favors homologous integration and employs reusable bidirectionally selectable markers. Appl. Environ. Microbiol. 77, 114-121. doi: 10.1128/AEM.02 100-10

Wang, D., Zhang, L., Zou, H., and Wang, L. (2017). Secretome profiling reveals temperature-dependent growth of Aspergillus fumigatus. Sci. China Life Sci. 61, 578-592. doi: 10.1007/s11427-0179168-4

Yoon, J., Kimura, S., Maruyama, J., and Kitamoto, K. (2009). Construction of quintuple protease gene disruptant for heterologous protein production in Aspergillus oryzae. Appl. Microbiol. Biotechnol. 82, 691-701. doi: 10.1007/ s00253-008-1815-5

Yu, J. H., Hamari, Z., Han, K. H., Seo, J. A., Reyes-Dominguez, Y., and Scazzocchio, C. (2004). Double-joint PCR: a PCR-based molecular tool for gene manipulations in filamentous fungi. Fungal Genet. Biol. 41, 973-981. doi: 10.1016/j.fgb.2004.08.001
Zhang, G., Zhu, Y., Wei, D., and Wang, W. (2014). Enhanced production of heterologous proteins by the filamentous fungus Trichoderma reesei via disruption of the alkaline serine protease SPW combined with a pH control strategy. Plasmid 71, 16-22. doi: 10.1016/j.plasmid.2014. 01.001

Conflict of Interest: The authors declare that the research was conducted in the absence of any commercial or financial relationships that could be construed as a potential conflict of interest.

Copyright (c) 2019 Qian, Zhong, Sun, Sun, Zhang, Liu, Qu and Zhong. This is an open-access article distributed under the terms of the Creative Commons Attribution License (CC BY). The use, distribution or reproduction in other forums is permitted, provided the original author(s) and the copyright owner(s) are credited and that the original publication in this journal is cited, in accordance with accepted academic practice. No use, distribution or reproduction is permitted which does not comply with these terms. 